\title{
Prevalence of diabetes, knowledge and attitude of rural population towards diabetes and hypoglycaemic event, Sudan 2013
}

\author{
Siham Ahmed Balla ${ }^{*}$, Haider Abu Ahmed, Mohamed Ali Awadelkareem \\ Department of Community Medicine, Faculty of Medicine, University of Khartoum, Khartoum, Sudan \\ Email address: \\ semam44@yahoo.com (S. A. Balla), dr.hayder2008@yahoo.com (H. A. Ahmed), maelkarim7@gmail.com (M. A. Awadelkareem)
}

\section{To cite this article:}

Siham Ahmed Balla, Haider Abu Ahmed, Mohamed Ali Awadelkareem. Prevalence of Diabetes, Knowledge and Attitude of Rural Population towards Diabetes and Hypoglycaemic Event, Sudan 2013. American Journal of Health Research. Vol. 2, No. 6, 2014, pp. 356-360.

doi: 10.11648/j.ajhr.20140206.16

\begin{abstract}
Introduction: The prevalence of diabetes mellitus is rising and needs adequate knowledge for its control. Objectives: The study aim was to identify prevalence of diabetes, population's knowledge, their attitude towards hypoglycemia event and factors associated with the level of knowledge. Material and Methods: A cross sectional study was carried out in a rural area of Sudan. The study population was 3316 adult males /females above 18 years of age. Structured questionnaire was used including eighteen questions to assess the knowledge about diabetes. Knowledge scores were recorded into adequate knowledge and inadequate knowledge. Attitude of diabetic and non-diabetic population was compared. Seven independent variables were included in logistic regression model to present the factors which contributed to adequate knowledge about diabetes. Results: The study included 1423 (42.9\%) males and 1893(57.1\%) females. The prevalence of diabetes in rural population was $11.2 \%$. Adequate knowledge about diabetes was $15 \%$. Genetics and nutrition habits were recognized as risk factors of diabetes by the population, $57.2 \% \& 46.9 \%$ respectively. Dizziness as a sign of hypoglycemia was mentioned (38.1\%) followed by rigors (24.4\%), sweating (21.4\%) and palpitation (17.1\%). Retinopathy (31.1\%) and cardiovascular diseases $(16.0 \%)$ were known by the study population as complications of diabetes. The response of diabetic population towards hypoglycemia event was significantly higher compared to non-diabetic, p-value 0.001. Gender, age, education, family history of diabetes, being a diabetic and smoker were contributory factors to knowledge. Conclusion: The prevalence of diabetes is increasing in rural population of Sudan. Knowledge about diabetes is low. A community based educational program is needed.
\end{abstract}

Keywords: Diabetes, Knowledge, Attitude, Factors, Rural, Sudan

\section{Introduction}

It was reported that 382 million were diabetic worldwide and $80 \%$ were living in low and middle income countries(1). These countries where more than $50 \%$ of population live in rural areas have shown rising trend of diabetes prevalence during last two decades(2). Prevalence of diabetes in Sudan is rising from $9.3 \%$ in 2010 to $10.6 \%$ in four states in 2013(3, 4). The level of awareness about diabetes was not searched adequately in developing countries(5). Studies in Asian countries showed poor and low knowledge about diabetes in rural areas (5-7). The level of awareness about diabetes was low even among diabetic population who suffered from complications of the disease(8). Although knowledge about diabetes risk factors and its complications were higher in urban population than rural but in both settings the knowledge about the disease was poor(9, 10). Individuals may not show any symptoms even when there is severe retinopathy and may present for the first time with severe hypoglycemia which may lead to coma and death $(11,12)$. Knowledge of population about diabetes types, risk factors and its complications could contribute to early detection and change the modifiable risk factors. This study aims to identify the prevalence of diabetes, assess the level of knowledge about diabetes and the contributory factors to the knowledge and the attitude of diabetic and non-diabetic population towards hypoglycemia event. 


\section{Material and Methods}

A descriptive community based study was carried out in four states of Sudan. The states were purposively selected (Gadarif, River Nile, Gazera and Northern). The study population was adult males / females above 18 years of age. The study units were the households that fulfilled the inclusion criteria of the study population. Two stage cluster sampling was used. The formula $n=$ Z2 P (1-P) / e2 multiplied by (design factor $=2$ ) at $95 \%$ Confidence level was used to estimate sample size. Since there was no data available about knowledge of any information about diabetes in the Sudan, $\mathrm{P}$ (prevalence) was chosen as $50 \%$. As knowledge is affected by behavioral factors(13) it was necessary to have large sample size so as to cater for variability of ethnicity in rural Sudan and to reduce the sampling error. To compensate for non-response and inappropriately filled questionnaires, $10 \%$ of the sample size was added.

The target sample size was 3380 adult individuals. The sample size was divided proportionally to the state population. Within each state, four clusters were selected. Non-response and incorrectly filled questionnaires were 64 (1.9\%) and the final sample subjected to analysis was 3316 individuals. Simple random sampling was used to select and interview adults who were eligible for inclusion in the study.

Structured questionnaire was used to interview the study population. It includes the variables of population characteristics and smoking status, presence of hypertension and diabetes and attitude towards hypoglycemia. Attitude was reflected by an open question and the answers were grouped and recoded.

Eighteen questions were included in the questionnaire to assess the knowledge about diabetes including types of diabetes, risk factors, and symptoms of hypoglycemia and diabetic complications.

Fifth year medical students in university of Khartoum were trained on filling the questionnaires. Data was cleaned, entered, and analyzed in SPSS version 20. Descriptive statistics was presented chi square test was used to test difference of diabetes prevalence in the four states at $95 \%$ confidence level.

Knowledge scores were recoded into adequate knowledge, $>=50 \%$ of the scores and inadequate knowledge, $<50 \%$ of the scores. Attitude was compared between diabetic and non-diabetic population.

Diabetes, hypertension, gender, age, smoking, education level and family history of diabetes were entered in logistic regression model as factors that contribute to knowledge.

\section{Results}

Population characteristics had shown $42.9 \%$ males and 57.1 females [Table 1]. The mean age was $39.6 \pm 15.5$ years and the median 38 years reflecting normal distribution curve with $65.1 \%$ above 30 years of age [Table 1]. Diabetic and hypertensive population accounted to $11.2 \%$ and $15.1 \%$ respectively [Table 1]. Family history of diabetes and smoking status were accounted to $48.3 \%$ and $12.7 \%$ respectively [Table 1].

Table 1. Characteristics of rural population in four States of Sudan

\begin{tabular}{llll}
\hline Population characteristics & $(\mathbf{n}=\mathbf{3 3 1 6})$ & $\mathbf{N}$ & $\mathbf{\%}$ \\
\hline \multirow{2}{*}{ Gender } & Male & 1423 & 42.9 \\
& Female & 1893 & 57.1 \\
Age, years & $=<30$ & 1158 & 34.9 \\
\multirow{4}{*}{ Hypertensive } & $>30$ & 2158 & 65.1 \\
\multirow{3}{*}{ Diabetic } & Yes & 501 & 15.1 \\
& No & 2815 & 84.9 \\
Family history of diabetes & Yes & 371 & 11.2 \\
& No & 2945 & 88.8 \\
Smoking & No & 1600 & 48.3 \\
& Yes & 1716 & 51.7 \\
\hline
\end{tabular}

${ }^{\#}$ Diabetic population who were smokers (12.9\%)

The overall prevalence of known diabetic population in four rural States in Sudan was $11.2 \%$ with significant variation between States, $p$-value $=0.001$ [Fig1]. The highest proportion of known diabetic population was in Gazera State (32.3\%) followed by River Nile State (29.6\%), Northern State (20.8\%) and Gadarif State (17.3\%) [Fig2].

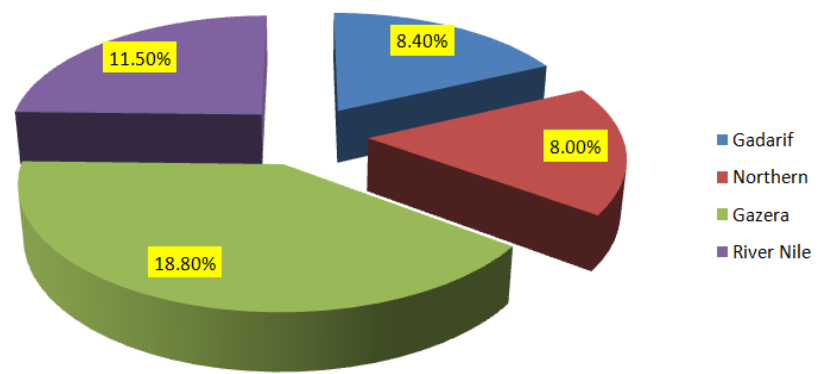

Fig 1. Prevalence of known diabetes among rural population Sudan 2013 $(n=3316)$

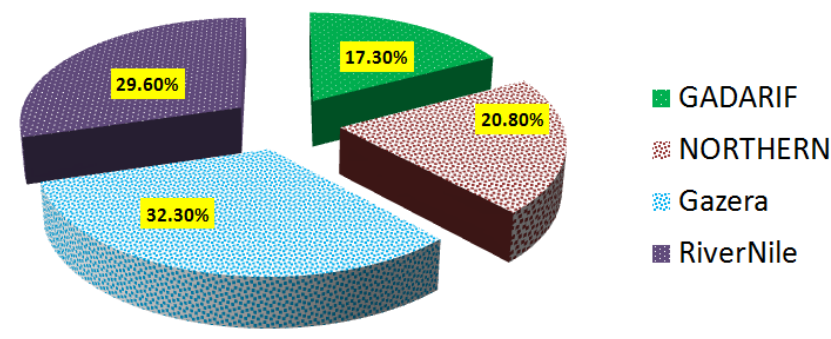

Fig 2. Proportions of population with diabetes by states,Sudan $2013 n=371$

The respondents identified genetics and nutritional habits as risk factors of diabetes, $57.2 \%$ and $46.9 \%$ respectively [Table 2]. Regarding knowledge about types of diabetes, $10.2 \%, 10.9 \%$ and $8.4 \%$ of the population knew type 1 , type 11 and gestational diabetes respectively [Table 2]. Dizziness was known by rural population as a sign of hypoglycemia (38.1\%) followed by rigors, sweating and palpitation, $24.4 \%$, $21.4 \%$ and $17.1 \%$ respectively [Table 2]. The most frequent known complication of diabetes was retinopathy (31.1\%) and 
the least frequent was cardiovascular diseases (16.0\%) [Table 2]

Table 2. Knowledge of rural population about diabetes, Sudan 2013

\begin{tabular}{lllc}
\hline Population`s Knowledge about Diabetes Mellitus (DM) & N & \%* \\
\hline \multirow{4}{*}{ Risk factors } & Genetics & 1897 & 57.2 \\
& Obesity & 715 & 21.6 \\
& Sedentary life & 671 & 20.2 \\
& Ageing & 464 & 14.0 \\
& Nutrition habits & 1554 & 46.9 \\
& break bad news & 91 & 2.7 \\
& Type 1 & 337 & 10.2 \\
Types of Diabetes & Type11 & 362 & 10.9 \\
& Gestational diabetes & 278 & 8.4 \\
& Sweating & 711 & 21.4 \\
Hypoglycaemia signs & Palpitation & 567 & 17.1 \\
& Rigors & 809 & 24.4 \\
& Dizziness & 1265 & 38.1 \\
& Peripheral neuropathy & 692 & 20.9 \\
& Cardiovascular diseases & 530 & 16.0 \\
& Retinopathy & 1031 & 31.1 \\
& Diabetic coma & 722 & 21.8 \\
& Septic foot & 978 & 29.5 \\
& Renal & 638 & 19.2 \\
\hline
\end{tabular}

*Multiple responses

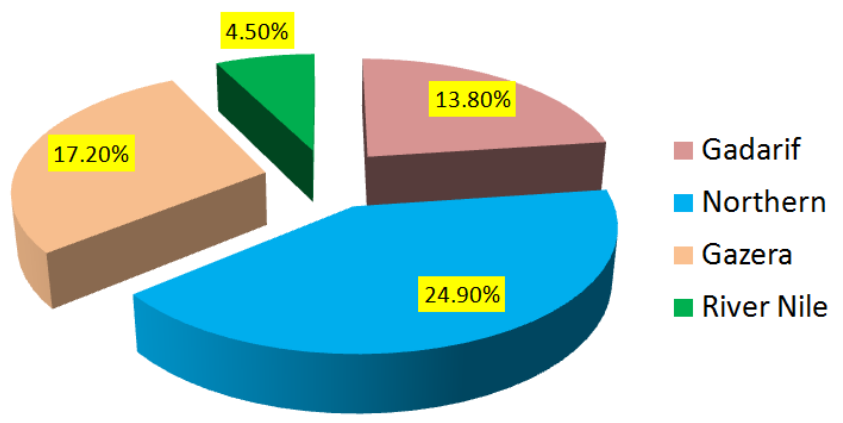

The prevalance of adequate knowledge about diabetes was $15 \%$

Fig 3. Prevalance of adequate knowledge about diabetes among rural population, Sudan 2013 ( $n=3316)$

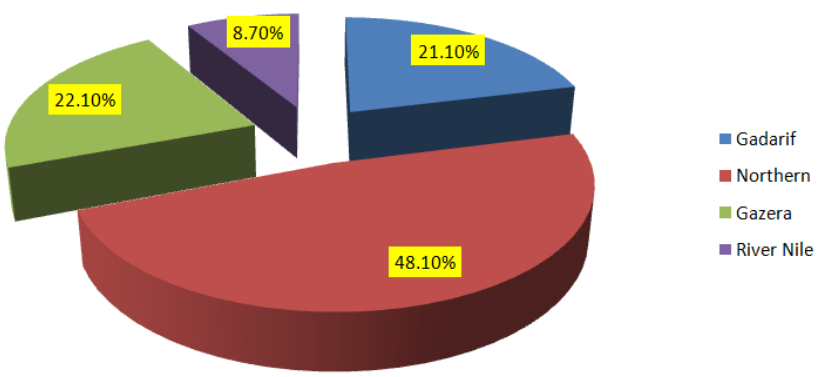

Fig 4. Proportion of population with adequate knowledge about diabetes by states Sudan $2013(n=497)$

Adequate knowledge about diabetes among rural population was $15 \%$ with significant variation between States p-value $<0.05[$ fig 3]. Diabetic population with adequate knowledge was $27.5 \%$ compared $13.4 \%$ of nondiabetic population. Northern State had the highest proportion of adequately knowledgeable population about diabetes (48.1\%) and River Nile State had shown the lowest proportion (8.7\%) [Fig 4]

The attitude towards hypoglycemia was significantly different between diabetic and non-diabetic population. Diabetic population has shown higher positive attitude more than non-diabetic, $94.6 \%$ versus $83.5 \%$ p-value 0.001 [Fig 5].

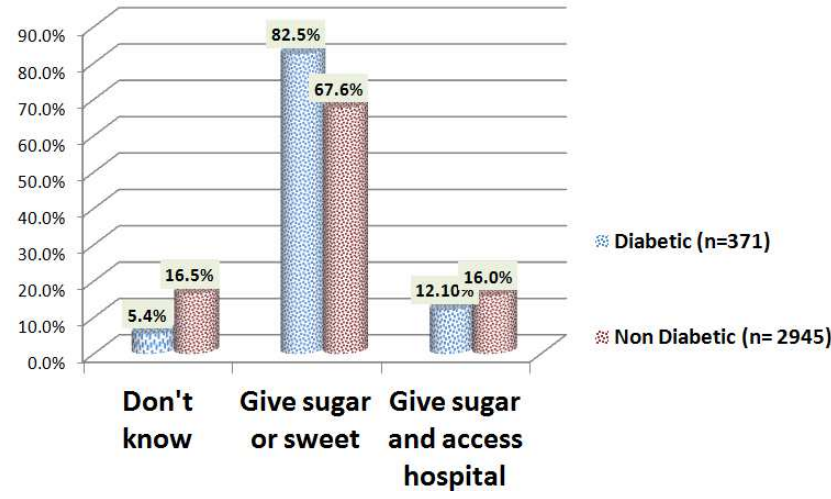

Fig 5. Attitude of rural population towards hypoglycemic event, Sudan 2013

Table 3. Factors contributed to knowledge about diabetes among rural population, Sudan 2013

\begin{tabular}{llll}
\hline Factors * & OR & 95\% CI & P-Value \\
\hline Gender (male) & 0.666 & $0.536,0.827$ & 0.001 \\
Age $>$ 30 years & 0.657 & $0.523,0.825$ & 0.001 \\
Education (higher level) & 0.310 & $0.250,0.385$ & 0.001 \\
Positive family of diabetes & 0.645 & $0.523,0.797$ & 0.001 \\
Diabetes & 0.420 & $0.317,0.557$ & 0.001 \\
Smoking & 0.661 & $0.499,0.876$ & 0.004 \\
\hline
\end{tabular}

*stepwise logistic regression at $95 \% \mathrm{CI}$

Table 3 showed the contribution of six factors to adequate knowledge of rural population. Males, age above 30 years, higher level of education, positive family history of diabetes, diabetes and smoking were contributing to knowledge about diabetes by $67 \%, 66 \%, 31 \%, 65 \%, 42 \%$ and $66 \%$ respectively.

\section{Discussion}

This study showed that $11.2 \%$ of rural population were known diabetic. This is consistent with the uprising trend of diabetes in low and middle income countries(14). The prevalence of diabetes in the four states was significantly different with the highest proportion in Gazera State and the lowest in Northern State. The prevalence in Northern State was low compared Sudan Household Survey 2010(15). The low prevalence of diabetes in Northern state could be attributed to the control program supported by World Diabetes Foundation. The program increased the knowledge of population about the risk factors of diabetes and that might contribute to the low prevalence. Diabetes and hypertension 
are interrelated diseases (16).In this study, the prevalence of hypertension was similar to rural Nigerian population(17).

The rural population in this study has adequate knowledge about genetics as a risk factor for diabetes compared to the knowledge of Indian population $(9,18)$. In this study, nutritional habits were known as risk factor for diabetes. This finding differs from a study carried out in Nigeria but is similar to case control studies designed for diabetic and nondiabetic population(19, 20). The Nigerian study determined the nutrition knowledge by specific nutrition items while in our study we used open question to reflect the real knowledge of the population about different food items.

Knowledge about signs and symptoms of hypoglycemia was low in our study compared to study conducted in outpatient clinic in Pakistan(21). This could be due to the large sample size in this study compared to the convenient sample in the study in Pakistan.

Knowledge about retinopathy as one of the complications of diabetes was low in this study compared to studies carried out in Oman and Kuwait $(22,23)$. The difference could be due to the demographic and socioeconomic composition of our rural population compared to high income countries.

The low rate of adequate knowledge about diabetes in our rural population is supported by several studies (24-27). Most of rural population has poor access to diabetic information(28)

Our rural population had shown significantly positive attitude towards hypoglycemic events with high rate among diabetic population. Attitude of population towards hypoglycemic event is vital since that more than $50 \%$ of hypoglycemic events occurred at home and hypoglycemia was identified as a predictor of several adverse outcomes $(29,30)$.

In this study, the factors contributed to knowledge about diabetes were diabetes status, being male, age above 30 years, and high level of education, smoking and family history of diabetes. Smokers in our study were found to have adequate knowledge about DM more than non-smokers by $66 \%$. Smoking as a contributory factor to knowledge about DM is a new finding of our study compared to other studies(23). This could be due to the proportion of diabetic population who were smokers in our study sample. Our finding is supported regarding sex and education in agreement with other studies where age and positive family history of diabetes were determinants of knowledge and poor knowledge was found among women and low level of education $(23,31-33)$.

\section{Conclusion}

The prevalence of diabetes in rural population in Sudan is high. Adequate knowledge about diabetes is low and attitude towards hypoglycemic events is positive with significant difference between diabetic and non-diabetic population. Sex, age, education, diabetes, family history of diabetes and smoking were factors that contribute to knowledge about diabetes. Well planned education program is needed in the rural community.

\section{Acknowledgement}

We extend our gratitude and thanks to Professor El Fatih Z. El Samani, the consultant of epidemiology for his valuable advises.

\section{References}

[1] Guariguata L, Whiting D, Hambleton I, Beagley J, Linnenkamp U, Shaw J. Global estimates of diabetes prevalence for 2013 and projections for 2035. Diabetes research and clinical practice. 2014;103(2):137-49.

[2] Hwang CK, Han PV, Zabetian A, Ali MK, Venkat Narayan K. Rural diabetes prevalence quintuples over twenty-five years in low-and middle-income countries: a systematic review and meta-analysis. Diabetes research and clinical practice. 2012;96(3):271-85.

[3] Balla SA, Abdalla AA, Elmukashfi TA, Ahmed HA. Hypertension among Rural Population in Four States: Sudan 2012. Global journal of health science. 2014;6(3):p206.

[4] CBS. Sudan Household Survey. In: statistics, editor. khartoum2010.

[5] Muninarayana C, Balachandra G, Hiremath S, Iyengar K, Anil N. Prevalence and awareness regarding diabetes mellitus in rural Tamaka, Kolar. International journal of diabetes in developing countries. 2010;30(1):18.

[6] Singh A, Milton PE, Nanaiah A, Samuel P, Thomas N. Awareness and attitude toward diabetes in the rural population of Arunachal Pradesh, Northeast India. Indian journal of endocrinology and metabolism. 2012;16(Suppl1):S83.

[7] Ulvi OS, Chaudhary RY, Ali T, Alvi R, Khan M, Khan M, et al. Investigating the awareness level about Diabetes Mellitus and associated factors in Tarlai (Rural Islamabad). J Pak Med Assoc. 2009;59:798-801.

[8] Foma MA, Saidu Y, Omoleke SA, Jafali J. Awareness of diabetes mellitus among diabetic patients in the Gambia: a strong case for health education and promotion. BMC Public Health. 2013;13(1):1124.

[9] Deepa M, Bhansali A, Anjana R, Pradeepa R, Joshi S, Joshi P, et al. Knowledge and awareness of diabetes in urban and rural India: The Indian Council of Medical Research India Diabetes Study (Phase I): Indian Council of Medical Research India Diabetes 4. Indian Journal of Endocrinology and Metabolism. 2014;18(3):379.

[10] Sabri AA, Qayyum MA, Saigol NU, Zafar K, Aslam F. Comparing knowledge of diabetes mellitus among rural and urban diabetics. McGill Journal of Medicine: MJM. 2007;10(2):87.

[11] Lewis K, Patel D, Yorston D, Charteris D. A qualitative study in the United Kingdom of factors influencing attendance by patients with diabetes at ophthalmic outpatient clinics. Ophthalmic epidemiology. 2007;14(6):375-80.

[12] Munshi MN, Segal AR, Suhl E, Staum E, Desrochers L, Sternthal A, et al. Frequent hypoglycemia among elderly patients with poor glycemic control. Archives of internal medicine. 2011;171(4):362-4. 
[13] Năftănăilă I. Factors Affecting Knowledge Transfer in Project Environments. Review of International Comparative Management; 2010.

[14] Hwang CK, Han PV, Zabetian A, Ali MK, Venkat Narayan KM. Rural diabetes prevalence quintuples over twenty-five years in low- and middle-income countries: A systematic review and meta-analysis. Diabetes research and clinical practice. 2012;96(3):271-85

[15] Health SNMo. Sudan Household Survey In: Directorate P, editor. Khartoum: CBS; 2010.

[16] Savoia C, Schiffrin E. Vascular inflammation in hypertension and diabetes: molecular mechanisms and therapeutic interventions. Clinical Science. 2007;112:375-84.

[17] Asekun-Olarinmoye E, Akinwusi P, Adebimpe W, Isawumi M, Hassan M, Olowe O, et al. Prevalence of hypertension in the rural adult population of Osun State, southwestern Nigeria. International journal of general medicine. 2013;6:317.

[18] Mohan D, Raj D, Shanthirani C, Datta M, Unwin N, Kapur A, et al. Awareness and Knowledge of diabetes in Chennai-The Chennai urban rural epidemiology study [CURES-9]. Journal of the Association of Physicians of India. 2005;53:283-7.

[19] Jasper US, Ogundunmade BG, Opara MC, Akinrolie O, Pyiki EB, Umar A. Determinants of diabetes knowledge in a cohort of Nigerian diabetics. Journal of Diabetes \& Metabolic Disorders. 2014;13(1):39.

[20] Fitzgerald N, Damio G, Segura-Pérez S, Pérez-Escamilla R. Nutrition knowledge, food label use, and food intake patterns among Latinas with and without type 2 diabetes. J Am Diet Assoc. 2008;108(6):960-7.

[21] Gul N. Knowledge, attitudes and practices of type 2 diabetic patients. J Ayub Med Coll Abbottabad. 2010;22(3):128-31.

[22] Khandekar R, Al Harby S, Al Harthy H, Al Lawatti J. Knowledge, attitude and practice regarding eye complications and care among Omani persons with diabetes-A cross sectional study. Oman journal of ophthalmology. 2010;3(2):60.

[23] Al-Adsani A, Moussa M, Al-Jasem L, Abdella N, Al-Hamad $\mathrm{N}$. The level and determinants of diabetes knowledge in Kuwaiti adults with type 2 diabetes. Diabetes \& metabolism. 2009;35(2):121-8.

[24] Maina WK, Ndegwa ZM, Njenga EW, Muchemi EW. Knowledge, Attitude and Practices related to Diabetes among Community Members in Four Provinces in Kenya: A Cross- sectional study. Journal of Pan African Medical, 7 (2), 1. $2011 ; 9$.

[25] Moodley L, Rambiritch V. An assessment of the level of knowledge about diabetes mellitus among diabetic patients in a primary healthcare setting. South African Family Practice. 2007;49(10):16-d.

[26] Baptiste-Roberts K, Gary TL, Beckles GL, Gregg EW, Owens $\mathrm{M}$, Porterfield D, et al. Family history of diabetes, awareness of risk factors, and health behaviors among African Americans. Am J Public Health. 2007;97(5):907-12.

[27] Kamel N, Badawy Y, El-Zeiny NA, Merdan I. Sociodemographic determinants of management behaviour of diabetic patients. Part II. Diabetics' knowledge of the disease and their management behaviour. Eastern Mediterranean health journal $=\mathrm{La}$ revue de sante de la Mediterranee orientale $=$ al-Majallah al-sihhiyah li-sharq al-mutawassit. 1999;5(5):974-83.

[28] Abdo NM, Mohamed ME. Effectiveness of Health Education Program For Type 2 Diabetes Mellitus Patients Attending Zagazig University Diabetes Clinic, Egypt. J Egypt Public Health Assoc. 2010;85(3-4):113-30.

[29] Leckie AM, Graham MK, Grant JB, Ritchie PJ, Frier BM. Frequency, Severity, and Morbidity of Hypoglycemia Occurring in the Workplace in People With Insulin-Treated Diabetes. Diabetes Care. 2005 June 1, 2005;28(6):1333-8.

[30] Zoungas S, Patel A, Chalmers J, de Galan BE, Li Q, Billot L, et al. Severe Hypoglycemia and Risks of Vascular Events and Death. New Engl J Med. 2010;363(15):1410-8. PubMed PMID: 20925543.

[31] Murugesan N, Snehalatha C, Shobhana R, Roglic G, Ramachandran A. Awareness about diabetes and its complications in the general and diabetic population in a city in southern India. Diabetes research and clinical practice. 2007;77(3):433-7.

[32] Rothman RL, Malone R, Bryant B, Wolfe C, Padgett P, DeWalt DA, et al. The Spoken Knowledge in Low Literacy in Diabetes Scale: A Diabetes Knowledge Scale for Vulnerable Patients. The Diabetes Educator. 2005 March 1, 2005;31(2):215-24.

[33] Chilton L, Hu J, Wallace DC. Health-Promoting Lifestyle and Diabetes Knowledge in Hispanic American Adults. Home Health Care Management \& Practice. 2006 August 1, 2006;18(5):378-85. 